\section{Interactive multimedia: Enhacing students' cognitive learning and creative thinking skill in Arthropod material}

\author{
Ubung Darmawan a,1,*, Sri Redjeki a,2, W. Widhorini a,3 \\ a Biology Education Studies Program, University of Kuningan, Jl. Pramuka No. 67, Kuningan Regency, West Java 45512, Indonesia \\ 1 darmawanubung@yahoo.com *; 2 sri.redjeki.n@gmail.com ; ${ }^{3}$ rinimrza@gmail.com \\ * Corresponding author
}

\section{ABSTRACT}

Interactive multimedia based on Adobe Director, as a learning medium, is important in optimizing students' learning outcomes. This study aimed to develop interactive multimedia in Arthropod topic as a learning media based on Adobe Director in optimizing students' cognitive learning outcomes as well as their creative thinking skills. This Research and Development (R \& D) adopted Lee and Owens model. The validity of the media developed was assessed by material and media experts. The product trial was done by involving ten of $X$ graders. The students' cognitive learning outcomes and creative thinking skills were measured using pretest and posttest. The data obtained were then analyzed using $\mathrm{N}$-gain calculation. The results showed that the interactive multimedia based on Adobe Director was categorized as feasible (based on material expert) and very feasible (based on media expert). The $\mathrm{N}$-gain scores of cognitive learning outcomes of $\mathrm{C} 1, \mathrm{C} 2, \mathrm{C} 3, \mathrm{C} 4$ were $0.70,0.75,0.71$, and 0.56 respectively. Moreover, the $\mathrm{N}$-gain scores of creative thinking skills were 0.55 (widening), 0.43 (connecting), and 0.73 (reorganizing). It can be concluded that the interactive multimedia based on Adobe Director developed is feasible and able to improve cognitive learning outcomes and students' creative thinking skills.

Copyright $\odot 2020$, Darmawan et al This is an open access article under the CC-BY-SA license

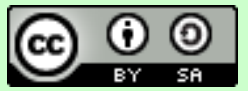

How to cite: Darmawan, U., Redjeki, S., \& Widhorini, W. (2020). Interactive multimedia: Enhacing students' cognitive learning and creative thinking skill in Arthropod material. JPBI (Jurnal Pendidikan Biologi Indonesia), 6(2), 257-264. doi: https://doi.org/10.22219/jpbi.v6i2.11370

\title{
INTRODUCTION
}

The $21^{\text {st }}$ century development made science and technology increasingly advanced and had a profound impact on education. One of the implementations of science and technology in education is multimedia-based learning. Research shows if the development of multimedia interactive learning increases student concepts (Gunawan, Harjono, Sahidu, \& Sutrio, 2014). Interactive multimedia can be interpreted as text, pictures, graphics, photos, sounds, videos, and animation presented interactively in the learning media (Akpinar, 2014; Barak, Ashkar, \& Dori, 2011). The learning process's dimension is the process of transmission of information so that the message can be conveyed without any translation failure by students. Multimedia interactive use can increase concept acquisition compared with conventional teaching (Angelides \& Agius, 2002; Markousis, Tsirikos, Vazirgiannis, \& Stavrakas, 2000). 
The multimedia interactive presented with interesting displays will embody interactions between students and media to not passive in learning. It is crucial to create superior learning that prioritizes results by giving learners high opportunities to participate more actively in the learning process. Nevertheless, multimedia's effectiveness on the study results and creative thinking skills depends on how the media is used and how the learning environment is built-in multimedia. Klerk, Eggen, \& Veldkamp, (2016) stated that while multimedia use may help students visualize abstract concepts, the standard multimedia design causes students to lack electronic awareness of computer-generated learning environments. They don't have the skills to find, process, and use information.

Recent studies related to this study include interactive multimedia studies in the southeastern United States (Schwartz \& Plass, 2014), in Germany (Domagk, Schwartz, \& Plass, 2010), and (Rasch \& Schnotz, 2009). Research related to multimedia interactive regarding the results of studying in Spain (Bayraktar, Cosgun, \& Altan, 2019) and in Bosnia (Dervic, Dapo, Mesic, \& Dokic, 2019). Research related to multimedia interactive toward creative thinking in Indonesia (Djamas, Tinedi, \& Yohandri, 2018; Gunawan, Harjono, Herayanti, \& Husein, 2019). Research related to multimedia interactive of study results and creative thinking on the arthropod matter has yet to be done. Thus, the study's improved outlook is that no one has yet developed multimedia interactive development for enhanced learning and creative thinking skills in Arthropod.

This research will contribute to education. That contribution was an innovation for struggling educators to teach Arthropod materials to students, as this multimedia interactive could develop students' learning and creative thinking skills while studying Arthropod matter. This study's contributions can also make it easier for students to learn Arthropod material, as these interactive multimedia designs encourage students to think creatively and illustrate Arthropod in detail. Arthropod organisms are complicated for students to do in-person learning observation activities, so with these multimedia, interactive could replace student viewing activities directly. The view of these interactive multimedia can give students a good picture of an Arthropod organism.

It developed multimedia interactive software as a learning medium on Arthropod material, and then applied it in-class learning to see how it affects the increasing results of students' creative learning and thinking. This study aims to develop biological learning media in interactive multimedia (based Adobe Director) Arthropod matter to know improved research and creative thinking skills.

\section{METHOD}

This research and development were adapted from Lee \& Owens, (2004) involved several phases that were (1) assessment and analysis; (2) instructional design; (3) development and implementation; (4) and evaluation. The aspect studied in the study is multimedia development. The interactive results of the students' cognitive and creative thinking skills on the Arthropod of this repression are performed from July to September 2019. The research units conducted on X MA PUI Kepuh, Lemahsugih District, Majalengka Regency involved 65 students made up of two samples: experiment classes and control classes.

In the need analysis phase, the observation sheet is used as an instrument to analyze the multimedia interactive and compatible syllabus in X MA PUI Kepuh, Lemahsugih District, Majalengka Regency. At the multimedia phase of model planning is made based: (1) sets a success indicator; (2) define procedures and develop instruments of judgment; (3) select a learning strategy; (4) selecting learning materials on the topic Arthropod. The multimedia development phase is the assembly of parts to be the first of the interactive multimedia products to be poured onto a hard disk or an extension file. Exe. Among the activities at this stage of product development are: (1) doing the gathering of materials, (2) the assembling or merging of materials; and (3) finish packing. Researchers also consult tutors, media experts, and materials experts to obtain the final results before entering the evaluation step in developing these multimedia products.

The product evaluation phase involves three types of evaluations: (1) ongoing evaluation is a continuous evaluation conducted researcher themselves from beginning to end, and informal; (2) formative assessment include alpha tests involving materials and media experts and then analysis and a first-stage revision; And the beta test involving educators, and $10 \mathrm{x}$ class learners (high, moderate and low) is followed by analysis and a final revision; and (3) the summation program/ evaluation of the final perfect product test of the development process that at the same time assesses the results of cognitive learning with an instrument of a 30-grain multiple-choice test and student creative thinking skill with a specifying instrument with an indicator of execution is formulated according to the aspect of creative thinking.

Creative thinking aspects include (1) sessions: recognizing a few things that can be identified from a given situation; (2) parallels: building mutual relationships between different elements; (3) building analogies between two different things; (4) synthesizing diversity from different elements into an overall structure; (5) retention: changing perspective/assuming a different point of view. Data analysis techniques were acquired from the 
validation of materials experts, media experts, and tests. Validation data to define multimedia interactive worthiness categories as learning media. Quantitative data the assessment of the material expert and the media expert is analyzed using qualitative descriptive statistics. The average assessments score from each assessor (Formula 1) is then converted into 5 qualitative data using conversion references from Sukarjo, (2006) in Table 1. Average ideal score $\left(X_{i}\right)=1 / 2$ (score $\max +$ score $\min$ ), ideal deviation standard $\left(S_{i}\right)=1 / 6$ (score max + score min), $X=$ empirical score. After using multimedia interactive to measure from $n$-gain scores on each such variable, increasing results of cognitive learning and creative thinking skills. These $\mathrm{N}$-gain scores are calculated using equations Formula 2 ( $S_{\text {post }}=$ score posttest, $S_{\text {pre }}=$ score pretest, $S_{\max }=$ score $\max$ ). The categories of N-gain: 1) $g>0,7$ (high); 2) $0,3<\mathrm{g} \leq 0,7$ (medium); 3) $0,3 \leq \mathrm{g}$ (low).

$$
\begin{aligned}
& \dot{x}=\frac{\Sigma \text { score obtained }}{\Sigma \text { ideal score }} \\
& g=\frac{\text { SPost }- \text { SPre }}{\text { SMax }- \text { SPre }}
\end{aligned}
$$

\begin{tabular}{|c|c|c|c|}
\hline \multirow{2}{*}{ Score } & \multirow{2}{*}{ Category } & \multicolumn{2}{|c|}{ Score } \\
\hline & & Formula & Amount \\
\hline 5 & Very good & $\overline{X l}+1,8 S d_{i}<X$ & $4,2<\bar{x}$ \\
\hline 4 & Good & $\overline{X l}+0,6 S d_{i}<X \leq \overline{X l}+1,8 S d_{i}$ & $3,4<\bar{x} \leq 4,2$ \\
\hline 3 & Average & $\overline{X l}-o, 6 S d_{i}<X \leq \overline{X l}+0,6 S d_{i}$ & $2,6<\bar{x} \leq 3,4$ \\
\hline $\begin{array}{l}2 \\
1\end{array}$ & $\begin{array}{l}\text { Poor } \\
\text { Very Poor }\end{array}$ & $\begin{array}{l}\bar{X} l-1,8 S d_{i}<X \leq \bar{X}-0,6 S d_{i} \\
X \leq \bar{X} l-1,8 S d_{i}\end{array}$ & $\begin{array}{l}1,8<\bar{x} \leq 2,6 \\
\bar{x} \leq 1,8\end{array}$ \\
\hline
\end{tabular}

Table 1. Interactive multimedia worthiness criteria

\section{RESULTS AND DISCUSSION}

The development study consists of four significant steps: (1) assessment and analysis; (2) instructional design; (3) development and implementation; (4) and evaluation (Lee \& Owens, 2004). Interactive Arthropod multimedia development began with research. This comprehensive analysis is a preliminary study by directly viewing conditions in the school environment and interviews with educators. The results of field analysis in (1) Arthropoda learning is considered one of the lesson materials that are difficult for learners to under; (2) a student's lack of enthusiasm for following the teaching of the Arthropoda material is because the material delivery is presented only by the teacher using the book medium and the; (3) educators rely solely on the conventional variations of teaching methods of speech, demonstration, and discuss; (4) educators are struggling with the transmission of Arthropoda mat; (5) the biological laboratories at schools have not been an option; (6) teachers have difficulty obtaining materials based media because the existing media is conventional and teachers have a desire to develop interactive media-based adobe director but have limited ab; (7) teachers need media appropriate to present conditions, which can attract students' attention and which is integral; (8) teachers and students need one media of multimedia interactive that can sustain the book media's learning process.

The analysis of the need for multimedia interactive based adobe director in MA Pui Kepuh is: (1) students think that they haven't had much more varied learning experiences; (2) the teacher more often uses the learning method in presenting the material by discussion only; (3) the use of a learning medium in the delivery of material of Arthropoda was very poor; (4) sometimes teachers use media when delivering materials but have not made students' attention increase because the media used only in PowerPoint forms has not been interactive; (5) students have difficulty absorbing the material presented by the teacher even though students should be thoroughly familiar with the material presented because after the material is finished, they will continue to practice.

A teacher's need analysis that explains the Arthropod learning process that takes place in the classroom. The opinion of the student who had trouble in the Arthropod mentioned above learning process was also approved by the teacher who profited from biology subjects. Teachers also say that he has difficulty creating interactive learning media. So, a teacher's practice can only describe and explain on the board or through pictures available in books only. It made up a lot of wasted time, and some of the students still did not understand the teacher's explanation, especially with the student sitting on the back. At the phase of planning design materials on interactive multimedia is Arthropod. A flowchart is also designed because the flowchart is a flow diagram of the plot in interactive multimedia production. It is also designed a storyboard that will describe the shape of each view. 
Strategy the learning sequence to be used in interactive multimedia includes (1) the learning sequence, which is the introduction of the desired competence and competency instruction, the presentation of complete material descriptions accompanied by examples and concluding of interactive problem exercises to know the level of students' understanding based on the materials learned; (2) the methods of learning used tend to be in individual teaching methods because students are faced with each computer and the application of the completed learning theory; (3) the material used in this interactive multimedia product is Arthropod; (4) the assessment form used in learning that uses multimedia interactive products is the learning result test. This test is used to measure the level of students' understanding of ability and insight in material mastery-the design of the multimedia interactive interface adobe director in Figure 1.

The sub-menu of each phylum Arthropod consists of a mind map, instructions, core $\&$ basic competence, material summaries, learning \& purpose indicators, interactive video menu, test menu, and audio (Figure 2). A prepared video display (Figure 3) has some benefits: full high definition video quality, interactive content, video can stop, when the cursor is pointed at one organ you will see. Organ reference it can be regenerated.

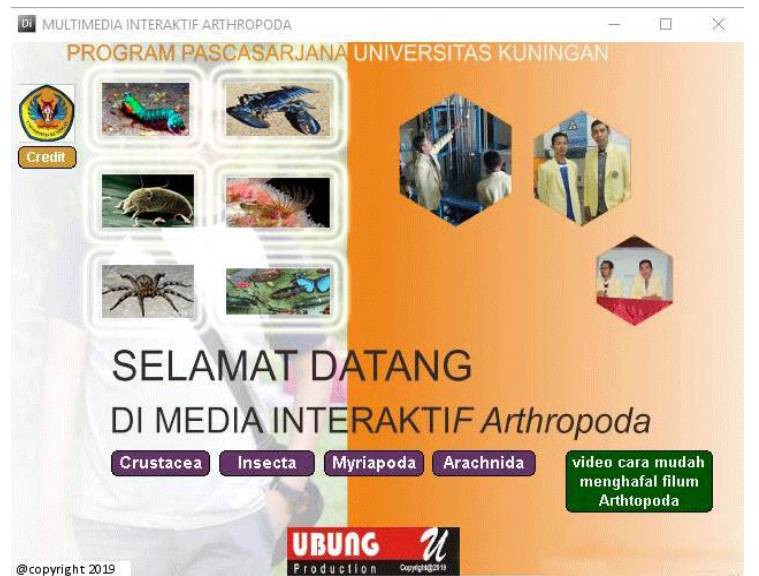

Figure 1. Interactive multimedia interface design based adobe director

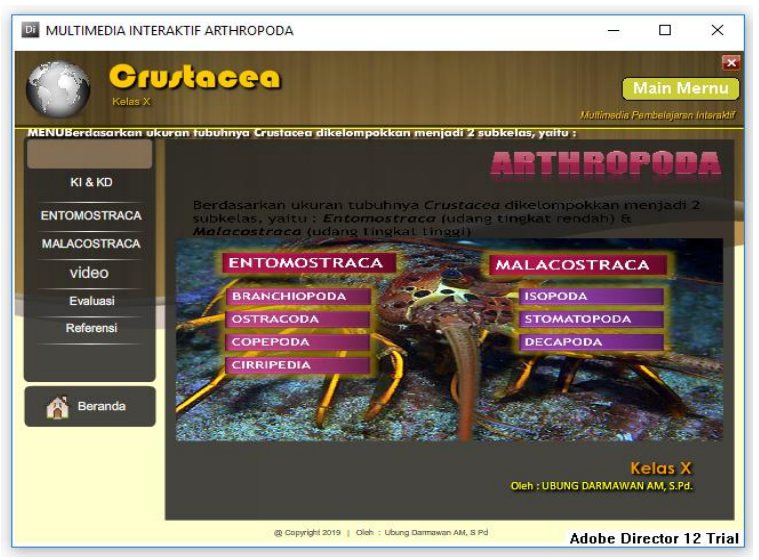

Figure 2. The menu of each of phylum Arthropod

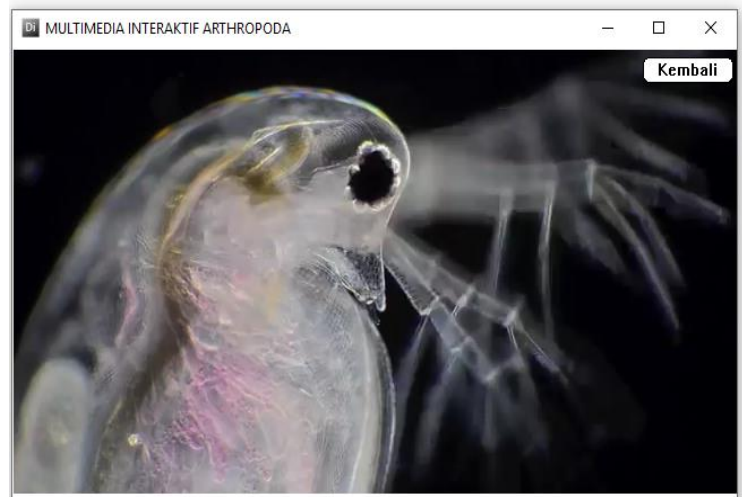

Figure 3. Full high definition video quality that has interactive media 
The overall development of interactive multimedia products discusses Arthropod material. This media production is also based on prototype designs, flowchart, and storyboards prepared earlier and other products that support it. The multimedia user target of X MA student. These multimedia items are packed in two storage shapes: in the form of extension, exe files stored in a drive, or a drive. All the materials prepared at the previous stage are combined to create multimedia interactive learning using the adobe director program.

The initial completed products are developed first by checking before the initial products are validated and tested by learners. In-house checking is initiated by starting with an overall course check. In an outline of this early stage of interactive learning products of development contains (1) use instruction serves to tell users how to use this multimedia interactive; (2) competence, which contains the standard formulas of competence, basic competence, indicators and purposes of learning; (3) Arthropoda matter; (4) evaluation, containing the practice of learned Arthropoda material. This exercise serves to check the level of students' understanding of the material they are studying; (5) games are interactive, which are some games related to materials that serve to see students' understanding as well as to existing materials; (6) the profile, which includes the profile of a developer, the media expert, and the profile of a material expert. There are two aspects assessed by experts in this alpha test as the aspect of learning and the material/content. Both aspects are described in 33 indicators with details of 20 learning aspects and 13 material/content aspects. The assessment data recapitulation of the two-aspect materials expert is presented in Table 2. The recapitulation shows the refraction of the expert assessments of the acquisition and materials at 4.48 , which shows an excellent score.

There are two aspects that media experts judge as programming and image aspects. Both aspects are described in 19 indicators with details of seven programming aspects and 12 aspects of view. The data of the two-aspect media expert is presented in Table 3. The results of the data show that the average media expert assessments on the programming aspect and the view are 4.45 that show excellent score. The trial of multimedia interactive learning products at each stage will be judged by students and revised according to the multimedia's flaws. The suggestions and criticizations of students given to each test will also be revised to perfect these interactive multimedia learning. Based on data analysis, it is known that students have increased cognitive learning results after the treatment. The material presented in the multimedia used in experimental groups is designed based on the principles of multimedia learning development to help students study. At the same time, the increased results of cognitive study per domain cognitive process are shown in Table 4.

Table 2. The results of experts' validation scores on multimedia interactive.

\begin{tabular}{clcc}
\hline No. & & Aspect & Score \\
\hline 1 & Teaching & & 4.35 \\
2 & Content / Material & & 4.61 \\
\hline & & Average & 4.48 \\
\hline
\end{tabular}

Table 3. The results of the media expert's validation score against.

\begin{tabular}{clcc}
\hline No & & Aspect of assessment & Score \\
\hline 1. & Programming & 4,57 \\
2. & Slideshow & & 4,33 \\
\hline & & Average & 4.45 \\
\hline
\end{tabular}

Table 4. The results of a student's cognitive learning test per domain cognitive process on Beta test.

\begin{tabular}{clcccc}
\hline \multirow{2}{*}{ No. } & \multirow{2}{*}{ Domain cognitive process } & \multicolumn{3}{c}{ Average } & \multirow{2}{*}{ Category } \\
\cline { 3 - 4 } & & Pre-test & Post-test & N- gain & \\
\hline I & Remember Cl & 37,50 & 81,25 & 0,70 & Medium \\
2 & Understanding C2 & 33,08 & 83,08 & 0,75 & High \\
3 & Application (C3) & 16,00 & 76,00 & 0,71 & High \\
4 & Analysis (C4) & 46,67 & 76,67 & 0,56 & Medium \\
\hline
\end{tabular}

Based on research on the cognitive test of the per-domain student may be described as follows: (1) domains $\mathrm{c} 1$ (remember) shows $\mathrm{N}$-gain 0.70 or occurs in medium (2) domains $\mathrm{c} 2$ (understanding) are in a high level with $\mathrm{N}$-gain 0.75 (3) domain $\mathrm{c3}$ (application) to $\mathrm{N}$-gain 0.71 is in high level and (4) the c4 domain (analysis) shows value $\mathrm{N}$-gain 0.56 or is in the medium scale. Thus, the treatment of interactive multimediabased adobe directors can enhance students' cognition with moderate and high $\mathrm{N}$-gain levels. The competence or cognitive assessment does measure the level of attainment or mastery of knowledge that includes memorization, understanding, application, analysis, synthesis, and evaluation (Agius \& Angelides, 2000; Dervic et al., 2019; Vazquez et al., 2019).

As to the effectiveness of multimedia interactive in improving creative thinking skills, data analysis on the validation of programs-interactive programs shows that overall, multimedia interactive improves student 
creative thinking skills more effectively than conventional media. As for the role of multimedia interactive in promoting creative thinking studied, multimedia is more effective at improving student creative thinking skills than conventional media (Gu, Dijksterhuis, \& Ritter, 2019; Perry \& Karpova, 2017; Schmid, 2008). In interactive media, opportunities for learners to respond or engage in activities that can also be reversed by multimedia programs, causing multimedia interactive can be designed by combining learning strategies to enhance students' creative thinking skills (Hidayat, Susilaningsih, \& Kurniawan, 2018; Huang, Chang, \& Chou, 2020; Kuk, Milentijevic, Rancic, \& Spalevic, 2012).

Its superiority is significantly in certain aspects consistent claimed that knowledge needed to be built into a student's early knowledge because it enabled him to make students aware of the unknown (Gould \& Anderson, 2002; Vagg, Balta, Bolger, \& Lone, 2020). Whereas on aspects of the matter and revalues, image-aided or animation information conveyances can make it easier for students to visualize and do a mental changeover to increase the retention aspect, no significant difference between the two groups of students even though the correct increase of both areas in the student group is learning to use higher multimedia (Jantz, Anderson, \& Gould, 2002; Meltzer, 2002). The interactive multimedia construct is intended to enhance creative thinking skills as a function of the overall production of products. The increased creative thinking skills came under greater emphasis on how the product's presentation integrated Torrence's learning activities. Increased creative thinking skills, when reviewed in terms of creative thinking, are indicated in Table 5.

Table 5. The results of the Students' creative think skills test every aspect on the Beta test.

\begin{tabular}{|c|c|c|c|c|c|}
\hline \multirow[b]{2}{*}{ No } & \multirow[b]{2}{*}{ Aspect } & \multicolumn{3}{|c|}{ Average } & \multirow[b]{2}{*}{ Category } \\
\hline & & Pre-test & Post-test & $\mathrm{N}$-gain & \\
\hline 1 & Widening & 46,50 & 76 & 0,55 & Medium \\
\hline 2 & Connecting & 36,43 & 64,29 & 0,43 & Medium \\
\hline 3 & Reorganizing & 38 & 83 & 0,73 & High \\
\hline
\end{tabular}

Some previous studies states a positive correlation between creative thinking and the results of students' cognitive learning. Skillful, creative thinking can induce students to form their conception of a phenomenon to become a correct concept and stored into their cognitive structure. In other words, creative thinking helps the student assimilate his or her knowledge (Huang, 2005; Low, Low, \& Koo, 2003; Oberholzer \& Hurni, 2000). This supports students' creative thinking skills.

\section{CONCLUSION}

The interactive multimedia product has been successfully developed through five development (need analysis, multimedia model design, multimedia development, product implementation, and multimedia valuation). It can be concluded that the interactive multimedia based on Adobe Director developed is feasible and able to improve cognitive learning outcomes and students' creative thinking skills. Multimedia interactive on the topic Arthropod that is worthy of being used as the science-learning medium for students $x$ class Aliyah. That worthiness is proven by the assessment of material experts and media experts. As for the multimedia interactive on the Arthropod topic, it has higher effectiveness than conventional learning in improving the results of student cognitive learning and creative thinking skills, and it is proven by student cognitive improvement and creative thinking skills.

\section{ACKNOWLEDGEMENT}

The gratitude and appreciation were given to the director of the Kuningan University's post-graduate school, who had granted permission and facilitated the study, the chairman of the undergraduate, the University of Kuningan, and the research team that had directed the research well.

\section{REFERENCES}

Agius, H. W., \& Angelides, M. C. (2000). A method for developing interactive multimedia from their semantic content. Data \& Knowledge Engineering, 34(2), 165-187. doi: https://doi.org/10.1016/S0169-023X(00)0 0014-8

Akpinar, E. (2014). The use of interactive computer animations based on poe as a presentation tool in primary 
science teaching. Journal of Science Education and Technology, 23, 527-537. doi: https://doi.org/10.10 07/s10956-013-9482-4

Angelides, M. C., \& Agius, H. W. (2002). An interactive multimedia learning environment for vlsi built with cosmos. Computers \& Education, 39(2), 145-160. doi: https://doi.org/10.1016/S0360-1315(02)00028-3

Barak, M., Ashkar, T., \& Dori, Y. J. (2011). Learning science via animated movies: its effect on students' thinking and motivation. Computers \& Education, 56(3), 839-846. doi: https://doi.org/10.1016/j.compedu .2010.10.025

Bayraktar, D. M., Cosgun, V., \& Altan, T. (2019). Cognitive load in multimedia learning environments: a systematic review. Computers \& Education, 141, 103618. doi: https://doi.org/10.1016/j.compedu.2019.103618

Dervic, D., Dapo, N., Mesic, V., \& Dokic, R. (2019). Cognitive load in multimedia learning: an example from teaching about lenses. Journal of Education in Science, Environment and Health, 5(1), 102-118. doi: https://doi.or g/10.21891/jeseh.481698

Djamas, D., Tinedi, V., \& Yohandri, Y. (2018). Development of interactive multimedia learning materials for improving critical thinking skills. International Journal of Information and Communication Technology Education (IJICTE), 14(4), 1-19. doi: https://doi.org/10.4018/IJICTE.2018100105

Domagk, S., Schwartz, R. N., \& Plass, J. L. (2010). Interactivity in multimedia learning: an integrated model. Computers in Human Behavior, 26(5), 1024-1033. doi: https://doi.org/10.1016/j.chb.2010.03.003

Gould, S. M., \& Anderson, J. (2002). Economic analysis of bilingual interactive multimedia nutrition education. Journal of Nutrition Education and Behavior, 34(5), 273-278. doi: https://doi.org/10.1016/S1499-4046(0 6)60106-1

Gu, X., Dijksterhuis, A., \& Ritter, S. M. (2019). Fostering children's creative thinking skills with the 5-I training program. Thinking Skills and Creativity, 32, 92-101. doi: https://doi.org/10.1016/j.tsc.2019.05.002

Gunawan, G., Harjono, A., Herayanti, L., \& Husein, S. (2019). Problem-based learning approach with supported interactive multimedia in physics course: its effects on critical thinking disposition. Journal for the Education of Gifted Young Scientists, 7(4), 1075-1089. doi: https://doi.org/10.17478/jegys.627162

Gunawan, G., Harjono, A., Sahidu, H., \& Sutrio, S. (2014). Penggunaan multimedia interaktif dalam pembelajaran fisika dan implikasinya pada penguasaan konsep mahasiswa. Jurnal Pijar MIPA, 9(1), 15-19. doi: https://doi.org/10.29303/jpm.v9i1.38

Hidayat, T., Susilaningsih, E., \& Kurniawan, C. (2018). The effectiveness of enrichment test instruments design to measure students' creative thinking skills and problem-solving. Thinking Skills and Creativity, 29, 161-169. doi: https://doi.org/10.1016/j.tsc.2018.02.011

Huang, C. (2005). Designing high-quality interactive multimedia learning modules. Computerized Medical Imaging and Graphics, 29(2), 223-233. doi: https://doi.org/10.1016/j.compmedimag.2004.09.017

Huang, N., Chang, Y., \& Chou, C. (2020). Effects of creative thinking, psychomotor skills, and creative selfefficacy on engineering design creativity. Thinking Skills and Creativity, 37, 100695. doi: https://doi.org/10.1016/j. tsc.2020.100695

Jantz, C., Anderson, J., \& Gould, S. M. (2002). Using computer-based assessments to evaluate interactive multimedia nutrition education among low-income predominantly hispanic participants. Journal of Nutrition Education and Behavior, 34(5), 252-260. doi: https://doi.org/10.1016/S1499-4046(06)60103-6

Klerk, S. D., Eggen, T. J. H. M., \& Veldkamp, B. P. (2016). A methodology for applying students' interactive task performance scores from a multimedia-based performance assessment in a bayesian network. Computers in Human Behavior, 60, 264-279. doi: https://doi.org/10.1016/j.chb.2016.02.071

Kuk, K., Milentijevic, I., Rancic, D., \& Spalevic, P. (2012). Pedagogical agent in multimedia interactive modules for learning - mimle. Expert Systems with Applications, 39(9), 8051-8058. doi: https://doi.org/ 10.1016/j.eswa.2012.01.138

Lee, W. W., \& Owens, D. L. (2004). Multimedia-Based Instructional design. In R. Taff (Ed.), Pfeiffer (2nd ed.). Wiley. Retrieved from https://bit.ly/3lKveKF

Low, A. L. Y., Low, K. L. T., \& Koo, V. C. (2003). Multimedia learning systems: a future interactive educational tool. The Internet and Higher Education, 6(1), 25-40. doi: https://doi.org/10.1016/S1096-7516(02)00160 $-4$

Markousis, T., Tsirikos, D., Vazirgiannis, M., \& Stavrakas, Y. (2000). Www-enabled delivery of interactive multimedia documents. Computer Communications, 23(3), 242-252. doi: https://doi.org/10.1016/S01403664(99)00178-4

Meltzer, D. E. (2002). The relationship between mathematics preparation and conceptual learning gains in 
physics: a possible "hidden variable" in diagnostic pretest scores. American Journal of Physics, 70(12), 1259-1268. doi: https://doi.org/10.1119/1.1514215

Oberholzer, C., \& Hurni, L. (2000). Visualization of change in the interactive multimedia atlas of switzerland. Computers \& Geosciences, 26(1), 37-43. doi: https://doi.org/10.1016/S0098-3004(99)00031-X

Perry, A., \& Karpova, E. (2017). Efficacy of teaching creative thinking skills: a comparison of multiple creativity assessments. Thinking Skills and Creativity, 24, 118-126. doi: https://doi.org/10.1016/j.tsc.2017.02.017

Rasch, T., \& Schnotz, W. (2009). Interactive and non-interactive pictures in multimedia learning environments: effects on learning outcomes and learning efficiency. Learning and Instruction, 19(5), 411-422. doi: https://doi.org/10.1016/j.learninstruc.2009.02.008

Schmid, E. C. (2008). Potential pedagogical benefits and drawbacks of multimedia use in the english language classroom equipped with interactive whiteboard technology. Computers \& Education, 51(4), 1553-1568. doi: https://doi.org/10.1016/j.compedu.2008.02.005

Schwartz, R. N., \& Plass, J. L. (2014). Click versus drag: user-performed tasks and the enactment effect in an interactive multimedia ebnvironment. Computers in Human Behavior, 33, 242-255. doi: https://doi.org/1 0.1016/j.chb.2014.01.012

Sukarjo. (2006). Kumpulan materi evaluasi pembelajaran. PPS UNY. Retrieved from http://library.pps.uny.ac.id/opac/inde $x$. php?p=show_detail\&id=6607

Vagg, T., Balta, J. Y., Bolger, A., \& Lone, M. (2020). Multimedia in education: what do the students think. Health Professions Education, 6(3), 325-333. doi: https://doi.org/10.1016/j.hpe.2020.04.011

Vazquez, F. L., Torres, A. J., Otero, P., Blanco, V., Lopez, L., Casal, A. G., \& Arrojo, M. (2019). Cognitivebehavioral intervention via interactive multimedia online video game for active aging: study protocol for a randomized controlled trial. Trials, 20, 692. doi: https://doi.org/10.1186/s13063-019-3859-5 